\title{
Do Investors Herd in Tunisian Financial Market during Political Crisis Period?
}

\section{Chouaib Hanafi}

\author{
Ecole Supérieure de Commerce, Manouba University (Tunisia) \\ E-mail:chou.hana@yahoo.com
}

\section{Ezzeddine Abaoub}

College of Administrative and Financial Sciences, Taif University, (Kingdom of Saudi Arabia)

E-mail: abaoub.ezzeddine@planet.tn

\section{Doi:10.5901/mjss.2016.v7n4p}

\begin{abstract}
The paper aims to examine the presence of herding behavior in the Tunisian stock market on two periods before and during the political and social crisis that took place in 2011. Examination of the presence of herding on market is based on the Cross Sectional Absolute Deviation of returns (CSAD) and consequently on the Chang, Cheng and Khorana (2000) model and its modified version introduced by Chiang and Zheng (2010) taking into consideration the effect of market conditions (when market is down or up) on herding. The study uses the relationship between the stock price and trading volume to detect herding. The empirical results indicate the presence of herd behavior during crisis period regardless to prices and trading volume movements. However, during the pre-crisis period herding is detected only when market is up.
\end{abstract}

Keywords: Herding behavior, Return dispersion, CSAD, Tunisian political crisis.

\section{Introduction}

Many studies have focused on the issue of herding behavior in financial markets by trying to analyze the causes and the impact of such behavior on the asset prices formation. According to Kremer and Nautz (2013), study on factors that lead investors to adopt herding behavior is an important step in understanding the effect of this behavior on the asset prices formation and determining the regulatory measures to be undertaken.

Shih et al (2015) defined herding as investors behavioral tendency to follow the actions of others. Bikhchandani and Sharma (2001) differentiated between "intentional herding" and "Spurious herding". Spurious herding is unwanted; it is the results of the reception of the same signals but with some delay. The intentional herding occurs when investor intentionally puts aside his private information and use other's information considered as more reliable.

Intentional herding is adopted by individual investors and institutional ones as well. Preservation of reputation is among factors that lead investors to adopt an intentional herding behavior. Indeed, for the sake of preserving their reputation, market investors adjust their investment decisions in accordance with the market leaders and therefore they engage in herding behavior. However as shown by Nofsinger and Sias (1999) institutional investors are more concerned with reputation preservation than individual investors, since the risk they are faced with, called reputational risk by Venezia et al (2011), is higher than individual investors' risk. According to Nofsinger and Sias (1999) it allows explaining the fact that the institutional herding in markets is higher than the individual one and that institutional herding effect on asset prices is higher than the individual herding.

Issues like private information quality and costs are also important factors that encourage investors to engage in herding behavior. Orlean $(1989,1995)$ argue that in periods of high volatility of asset prices, the uncertainty in the financial markets affects the costs of obtaining information by making it more expensive, as well as time needed to obtain and to process this information by making them higher. In such circumstances, investors engage in herding behavior, since, if they decide on based on their own information, they incur very high costs. However, even in the extreme case where investor has no information, by following others, he avoids to deviate from the average opinion of the market and to undergo a risk caused by a randomly taken decision. According to Mensah and Yang (2008), this behavior appears rational because when the investor engage in herding behavior, he is adopting a strategy that is better and less risky than taking a random decision. Thus Venezia et al (2011) suggest that herding deepen during periods with high volatility in asset prices as well as during periods of uncertainty about the fundamental value. 
So we are wondering if political instability and social troubles lead the financial markets investors to engage in herding behavior. Dimic et al (2015) empirical study proved that asset returns are affected by the risk caused by political instability. According to Bilson et al (2002) the influence of this risk on the asset return is more visible on emerging markets than developed ones. Chau et al (2014) have shown that political troubles in some Arab countries increased stock prices volatility.

This paper is to investigate whether the social and political crisis that took place in Tunisia from the year 2011 brought herding behavior in the Tunisian financial market. The underlying idea is that, during political uncertainty periods, investors engage in herding behavior in order to avoid deviating from the average opinion of the market. Some empirical studies have focused on the effect of financial crises in herding behavior emergence. Nevertheless, the study of the impact of political uncertainty on herding behavior is a subject that still lacks analysis. We therefore consider that this study enriched the empirical literature on this subject and allows bringing more light to the phenomenon of herding behavior. This behavior was considered by some authors as one of the causes of financial markets inefficiency, abnormal asset prices formation and speculative bubbles rising (Kremer and Nautz (2013)).

The paper consists of six sections. Section 2 briefly introduces the Tunisian stock exchange. The theoretical models of herding behavior based on the Cross Sectional Absolute Deviation of returns (CSAD) are presented in section 3. In section 4, a description of the methodology and data is given. The empirical results are detailed in section 5 and the concluding remarks are in section 6 .

\section{Tunisian Stock Exchange}

Tunis Stock Exchange is an emerging market in North Africa. It was created in 1969. As a result of the modernization and the development of the regulatory and technical framework, the Tunisian financial market has experienced a significant activity growth since the late 1990s. In fact, the number of listed companies has risen steadily from 38 companies in 1998 (year in which the new index "TUNINDEX" was launched) to 77 companies in 2014. In 2010, TUNINDEX increased for the eighth time since 2003 and it reached record highs on several occasions. In January 2011, the popular uprising and the fall of the regime brought a period of political and economic instability throughout the country. These events have prompted the financial market authority to suspend the quotation during 15 trading days, from 17th to 31st January and from 28th February to 4th Marsh. In the first two months of 2011, TUNINDEX recorded a cumulative drop of 20.62\%. Since 2011, The Tunisian financial market has been exposed to strong political uncertainties. In fact, in Tunisia since the end of 2012, there have been some terrorist bombings, two political assassinations (in 6th February 2013 and in 25th July 2013) and two spectacular attacks: the bombing of the museum of Bardo and in the coastal city of Sousse (occurred in the 18th March and 26th June 2015 respectively). As shown in Figure 1, the impact of these events on the evolution of TUNINDEX was significant.

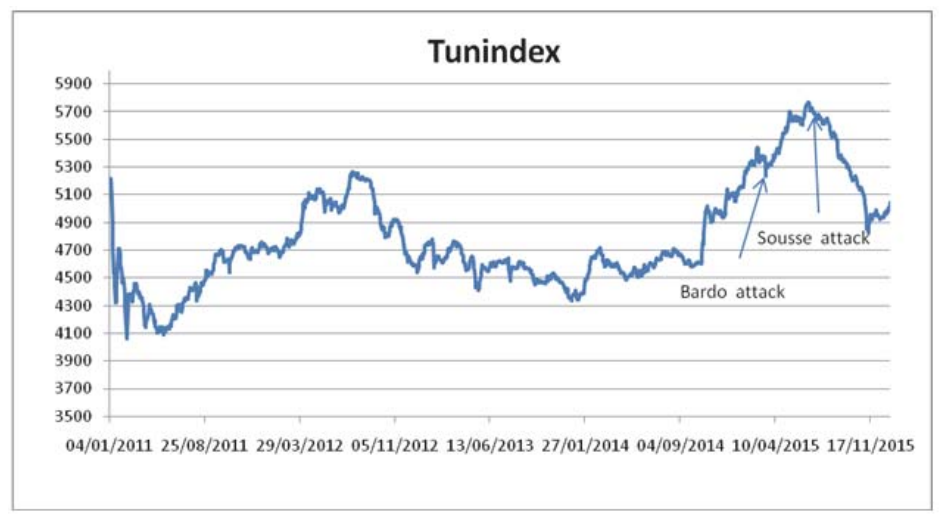

Figure 1: The evolution of Tunindex during the period of the political and the social crisis ${ }^{1}$

\footnotetext{
${ }^{1}$ Note: This figure represents the evolution of Tunindex during the period of the political and the social crisis in Tunisia which runs from 1st January, 2011 to 31st December, 2015.
} 


\section{Models of Herding Behaviour}

Modeling and testing herding behavior is not an easy task because it is difficult to validate a mainly psychological and unquantifiable behavior. However, one of the approaches developed for the detection of this behavior on the financial markets is based on the return dispersion.

\subsection{Christie and Huang (1995) model}

Christie and Huang (1995) proposed an approach to test herding behavior based on the Cross-Sectional Standard Deviation of returns (CSSD), defined as:

$$
\operatorname{CSSD}_{t}=\sqrt{\frac{\sum_{i=1}^{N}\left(R_{i, t}-R_{m, t}\right)^{2}}{N-1}}
$$

Where $R_{i, r}$ the return of stock i at time $\mathrm{t}, R_{m, t}$ is the cross-sectional average return of $\mathrm{N}$ stocks of the sample at time t.

It was argued by Christie and Huang (1995) that during periods of extreme market movements, investors are more favourable to engage in a herding behavior to avoid deviating from the average opinion of the market. So that the individual asset returns would be close to the average return of the market and thus, a low CSSD during these periods. Thus, the presence of a herding behavior can be expected by an increase in return dispersion less proportional to extreme values of return in the market.

Christie and Huang (1995) present the following linear relationship to test herding behavior on the financial market:

$$
\operatorname{CSSD}_{t}=\alpha+\beta^{L} I_{t}^{L}+\beta^{U} I_{t}^{U}+\varepsilon_{t}
$$

Where $I_{t}^{L}$ is a dummy variable that equals one if the market return on day $t$ lies in lower tail of return distribution, and zero otherwise and $I_{t}^{U}$ a second dummy variable that equals one if the market return on day $t$ lies in the upper tail of return distribution, and zero otherwise. ${ }^{\varepsilon_{t}}$ is the error term at time t. Negative and statistically significant values of $\beta^{L}$ and $\beta^{U}$ indicate the presence of herding behavior.

\subsection{Chang, Cheng and Khorana (2000) model}

Chang et al (2000) propose another measure of return dispersion, based on the Cross-Sectional Average Deviation of returns (CSAD), and defined as ${ }^{(2)}$ :

$$
\operatorname{CSAD}=\frac{1}{N} \sum_{i=1}^{N}\left|R_{i, t}-R_{m, t}\right|
$$

Chang et al (2000) consider that when herding behavior is not present, and as provided by the rational asset pricing models, returns dispersion increases with the absolute value of market's average return and the relationship between CSAD and the absolute value of the average return is assumed to be linear. The emergence of herding behavior is likely to make this relationship nonlinear and statistically decreasing. Chang et al (2000) therefore propose to test the following model, referred as model I, in order to detect herding behavior in financial market:

$$
\operatorname{CSAD}_{t}=\gamma_{0}+\gamma_{1}\left|R_{m, t}\right|+\gamma_{2} R_{m, t}^{2}+\varepsilon_{t}
$$

Herding is proven if the relationship between the return dispersion, the CSAD and the average return is non-linear and negative, i.e. if $\hat{\gamma}_{2}$ coefficient is negative and statistically significant.

\subsection{Sensitivity of herd behavior to market conditions}

Herding behavior may change depending on the market conditions, i.e. up and down price movements. Chiang and Zheng (2010) introduced a dummy variable to the model developed by Chang et al (2000) in order to take into account market conditions. The dummy variable, $D=1$ when market is down, when the average returns is negative, and 0 otherwise. Thus the model linking the CSAD to the one presented by Chiang and Zheng (2010) taking into account herding behavior sensitivity to market conditions, referred as model II, is as follows:

\footnotetext{
2 The same variables definitions were retained as in the CSSD.
} 


$$
C_{1} A D_{1}=\varphi_{0}+\varphi_{1}(1-D)\left|R_{m, t}\right|+\varphi_{2} D\left|R_{m, t}\right|+\varphi_{3}(1-\mathrm{D}) R_{m, t}^{2}+\varphi_{4} D R_{m, t}^{2}+\varepsilon_{t}
$$

Where $\mathrm{D}$ a dummy variable equals one when market is down and zero otherwise.

Herding when market is up (or down) results in a negative relationship between the CSAD and the squared return $R_{m}^{2}$ shown by negative and significant $\hat{\varphi}_{3}\left(\hat{\varphi}_{4}\right)$ coefficient.

\subsection{Some results of the empirical studies}

Several studies based on the return dispersion approach and the CSSD and CSAD indicators to detect herding behavior presence in financial markets, are developed respectively by Chang et al (2000) and Christie and Huang (1995). By considering these two indicators, the CSAD and the CSSD, as herding measure, Lam and Qiao (2015) have shown the presence of herding behavior on Hong Kong financial market and have shown also that this behavior is related to up movement of stock prices. Le and Truong (2014) have shown the superiority of the CSAD indicator compared to the CSSD in herding behavior detection on the Vietnamese market. By dividing the whole period of study that runs from 2006 to 2011 into six annual periods, Le and Truong (2014) have shown that herding behavior is present only during the years 2008 and 2009 on the Vietnamese market. Chang and Lin (2015) empirical study was based on a sample of 50 countries and has shown herding behavior present only in 18 countries $^{3}$. Bhaduri and Mahapatra (2013) investigated the possibility of the emergence of herding behavior on the Indian financial market and have shown that herding is present on periods of major crashes that occurred from 2006 to 2008. By grouping the 689 firms listed on Taiwanese stock market in 19 sectors, Demier et al (2010) have shown the emergence of herding behavior for all sectors except the tourism and automotive sectors and found that herding behavior is present on days when the market is down. Chiang and Zheng (2010) have confirmed, based on 18 financial markets grouped into 7 developed markets, 7 Asian markets and 4 Latin America markets, that herding behavior is present in all Asian markets and in developed markets except the United States while for the Latin American markets herding was absent.

\section{Methodology and Data Description}

\subsection{Methodology}

The paper focus on herding behavior in the Tunisian financial market during two different periods: before and during the Tunisian political and social crisis of the $14^{\text {th }}$ of January 2011.

Given that, by its design, Christie and Huang (1995) model allow detecting the herd behavior only during the extreme returns periods, i.e. periods of high volatility of stock prices, it seems inappropriate for the detection of this behavior on the Tunisian stock market, during the selected period of study. Thus this study will be based on the methodology given by Chang et al (2000) and by its modified version introduced by Chiang and Zheng (2010) which takes into consideration the effect of market conditions on herding (models I and model II respectively).

We also suggest an approach based on the relationship between stock price and trading volume to detect herding presence. Trading volume is considered as an important factor in detecting herding behavior because it carries significant information about investors' behavior in the financial market.

The positive relationship between stock prices and trading volume, verified in empirical works dealing with issue (Crouch (1970), Lee and Rui (2002) among other), reveals that, like the average stock returns, when herding is present, the relationship between CSAD and average volume is nonlinear.

The relationship between the CSAD, average stock market return and trading volume (model III) is as follows:

$C S A D,=\eta_{0}+\eta_{1}\left|R_{m, t}\right|+\eta_{2} R_{m, t}^{2}+\eta_{3}\left|V_{m, t}\right|+\eta_{4} V_{m, t}^{2}+\varepsilon_{t}$

Where, $V_{m, t}=\log \left(v_{m, t} / v_{m, t-1}\right)$ and $v_{m, t}$ is the daily trading volume weighted by market capitalization.

So, a negative and significant $\eta_{4}$ coefficient means that the relationship between CSAD and volume is negative and nonlinear which is an evidence of herding behavior presence. In order to investigate the sensitivity of herding behavior to trading volume movements, we suggest introducing dummy variables to differentiate increasing and decreasing trading volume periods, called $D_{v}^{\text {wr }}$ and $D_{v}^{\text {atom }}$ respectively. The relationship between the CSAD, the average stock return when the volume is increasing or decreasing (model IV) is as follow:

${ }^{3}$ Herding behavior is detecting in 18 stock markets of Australia, Austria, Chile, China, Hong Kong, Hungary, Ireland, Japan, Malaysia, Poland, Portugal, Switzerland, Taiwan, Thailand, Turkey, UK, US and Venezuela. 
$C S A D_{t}=\theta_{0}+\theta_{1} \mathrm{D}_{\mathrm{V}}^{\text {up }}\left|R_{m, t}\right|+\theta_{2} D_{V}^{\text {down }}\left|R_{m, t}\right|+\theta_{3} \mathrm{D}_{\mathrm{V}}^{\text {up }} R_{m, t}^{2}+\theta_{4} D_{v}^{\text {down }} D R_{m, t}^{2}+\varepsilon_{t}$

$D_{v}^{u p}=1$ when volume is increasing and 0 otherwise.

$D_{r}^{\text {down }}=1$ when the volume is decreasing and 0 otherwise.

\subsection{Data description}

The study uses a sample of 72 companies on the Tunisian stock exchange ${ }^{4}$. The study covers the period starting from $1^{\text {st }}$ January, 2006 to $31^{\text {st }}$ December, 2015. The stock returns and the trading volume were taken on daily basis. The period preceding the political and social crisis in Tunisia is from $1^{\text {st }}$ January, 2006 to $31^{\text {st }}$ December, 2010 whereas the crisis period is from $1^{\text {st }}$ January, 2011 to $31^{\text {st }}$ December, 2015. The statistical description of the variables used in the study is given in Table 1.

Table 1: Statistical description of the used variables

\begin{tabular}{|c|c|c|c|c|c|c|c|c|c|}
\hline & \multicolumn{3}{|c|}{ Whole period } & \multicolumn{3}{c|}{ Pre-crisis period } & \multicolumn{3}{c|}{ Crisis period } \\
\hline & $R_{m, t}$ & $V_{m, t}$ & $C S A D_{t}$ & $R_{m, t}$ & $V_{m, t}$ & $C S A D_{t}$ & $R_{m, t}$ & $V_{m, t}$ & CSAD \\
\hline Mean & -0.018 & -0.007 & 1.02 & 0.004 & -0.006 & 1.074 & -0.040 & -0.008 & 0.966 \\
\hline Median & 0.008 & -0.002 & 0.937 & 0.054 & -0.012 & 0.946 & -0.025 & 0.008 & 0.922 \\
\hline Maximum & 3.10 & 2.24 & 10.61 & 2.652 & 1.260 & 10.611 & 3.105 & 2.241 & 4.39 \\
\hline Minimum & -5.47 & -1.88 & 0.29 & -5.472 & -1.311 & 0.316 & -3.475 & -1.878 & 0.291 \\
\hline Std. Dev & 0.56 & 0.38 & 0.64 & 0.647 & 0.372 & 0.844 & 0.453 & 0.39 & 0.304 \\
\hline Skewness & -2.81 & -0.14 & 9.14 & -3.360 & -0.040 & 7.578 & -0.939 & -0.228 & 2.416 \\
\hline Kurtosis & 25.44 & 4.64 & 110.40 & 25.091 & 3.456 & 69.358 & 15.364 & 5.599 & 19.573 \\
\hline Jarque-Bera & 55222 & 286 & 1224092 & 27592 & 11.080 & 239768 & 8035.2 & 357.96 & 15311.4 \\
\hline N & 2475 & 2475 & 2475 & 1242 & 1242 & 1242 & 1233 & 1233 & 1233 \\
\hline
\end{tabular}

It is noted from Table 1 that the average return is positive during the pre-crisis period and negative during the crisis period. Over the studied periods, the asymmetry coefficient (skewness) of the three series is different from zero, which indicates the presence of asymmetry and contradicts the hypothesis of a linear Gaussian normal distribution. In addition, all three time series have thicker tails than a normal distribution since the "kurtosis" is greater than 3 (the value of the kurtosis coefficient for a normal distribution). The non-normality of the series is also confirmed by the Jarque-Bera Test which indicates high kurtosis values for the studied periods.

Based on the Augmented Dickey-Fuller (ADF) test of market return, market volume and CSAD, these time series are stationary as shown in table 2.

Table 2: ADF Test results

\begin{tabular}{|c|c|c|c|c|c|c|}
\hline \multirow{2}{*}{ Period } & \multirow{2}{*}{ Variable } & \multirow{2}{*}{ ADF-t } & \multirow{2}{*}{ Critical Value (5\%) } & \multicolumn{2}{|c|}{ Model } & \multirow{2}{*}{ Conclusion } \\
\hline & & & & Constant & Trend & \\
\hline \multirow{3}{*}{ Whole period } & $R_{m, t}$ & -39.56 & -1.94 & No & No & Stationnary \\
\hline & $V_{m, t}$ & -34.69 & -2.86 & Yes & No & Stationnary \\
\hline & $C S A D_{\text {, }}$ & -18.66 & -3.41 & Yes & Yes & Stationnary \\
\hline \multirow{3}{*}{ Pre-crisis period } & $R_{m,}$ & -29.93 & -1.94 & No & No & Stationnary \\
\hline & $V_{n}$ & -28.78 & -1.94 & No & No & Stationnary \\
\hline & $C S A D_{t}$ & -29.68 & -2.86 & Yes & No & Stationnary \\
\hline \multirow{3}{*}{ Crisis period } & $R_{m}$ & -24.37 & -2.86 & Yes & No & Stationnary \\
\hline & $\overline{V_{m}}$ & -24.27 & -1.94 & No & No & Stationnary \\
\hline & $C S A D_{i}$ & $\begin{array}{l}-9.38 \\
\end{array}$ & -2.86 & Yes & No & Stationnary \\
\hline
\end{tabular}

\footnotetext{
${ }^{4}$ Listed companies with more than $50 \%$ missing observations were not selected in the sample composition.
} 


\section{Herding Behavior Tests Results}

\subsection{Tests of herding behavior on the Tunisian financial market}

Table 3 shows the results of the regression of model I. The results indicate that during the whole period and the pre-crisis period, all coefficients are positive and significant. The relationship coefficient between CSAD and squared return $R_{m, t}^{2}$ is positive which demonstrate the absence of herding behavior. However, the test results show that during the crisis period,

all the coefficients are significant and the relationship coefficient between CSAD and $R_{m, t}^{2}$ is negative $\left(\hat{\gamma}_{2}=-0,144\right)$. This indicates that the relationship between CSAD and market return is non linear confirming the presence of herding behavior during the crisis period. So according to the model I test results, herding is present during the political crisis period on the Tunisian financial market.

Table 3: Model I empirical estimation

\begin{tabular}{|c|c|c|c|c|}
\hline \multicolumn{5}{|c|}{ Model I: CSAD ${ }_{t}=\gamma_{0}+\gamma_{1}\left|R_{m, t}\right|+\gamma_{2} R_{m, t}^{2}+\varepsilon_{t}$} \\
\hline & $\hat{\gamma}_{0}$ & $\hat{\gamma}_{1}$ & $\hat{\gamma}_{2}$ & Adj. $\mathrm{R}^{2}$ \\
\hline Whole period & $\begin{array}{c}0.838^{*} \\
(82.69)\end{array}$ & $\begin{array}{c}0.284^{*} \\
(9.39)\end{array}$ & $\begin{array}{l}0.278^{*} \\
(31.7)\end{array}$ & 0.74 \\
\hline Pre-crisis period & $\begin{array}{c}0.813^{*} \\
(53.43)\end{array}$ & $\begin{array}{l}0.378^{*} \\
(8.91)\end{array}$ & $\begin{array}{c}0.286^{*} \\
(26.12)\end{array}$ & 0.83 \\
\hline Crisis-period & $\begin{array}{c}0.756^{*} \\
(69.76)\end{array}$ & $\begin{array}{c}0.821^{*} \\
(20.78)\end{array}$ & $\begin{array}{c}-0.144^{*} \\
(-8.25)\end{array}$ & 0.41 \\
\hline
\end{tabular}

The numbers between parentheses are $p$-value. Adj. $\mathrm{R}^{2}$ is the adjusted R-squared. * represent statistical significance at the $1 \%$ level.

\subsection{Tests of herding sensitivity to market conditions}

Study of herding sensitivity to market conditions shows that for the three considered periods (the whole period, the precrisis period and political crisis period), all coefficients of the model II are significant and $\hat{\varphi}_{3}$ coefficient is negative, letting to conclude that during these periods herding is associated to market up, i.e. to days of positive market return. However, it appears from the tests results that herding behavior is related to down market only during the crisis period since the $\hat{\varphi}_{4}$ coefficient is negative only for the crisis period $\left(\hat{\varphi}_{4}=-0126\right)$. Thus, the period of political crisis is characterized by the presence of herding behavior in the Tunisian stock market and this behavior is present when market is up and down. In addition, it appeared that herd behavior is stronger when market is up since $\left|\hat{\varphi}_{3}\right|$ is higher than $\left|\hat{\varphi}_{4}\right|$.

Table 4: Model II empirical estimation

\begin{tabular}{|c|c|c|c|c|c|c|}
\hline \multicolumn{2}{|c|}{ Modelll : $C S A D_{,}=\varphi_{0}+\varphi_{1}(1-D)\left|R_{m, t}\right|+\varphi_{2} D\left|R_{m, t}\right|+\varphi_{3}(1-D) R_{m, t}^{2}+\varphi_{4} D R_{m, t}^{2}+\varepsilon_{t}$} \\
\hline Periods & $\hat{\varphi}_{0}$ & $\hat{\varphi}_{1}$ & $\hat{\varphi}_{2}$ & $\hat{\varphi}_{3}$ & $\hat{\varphi}_{4}$ & Adj. $\mathrm{R}^{2}$ \\
\hline \multirow{2}{*}{ Whole period } & $\begin{array}{c}0.8^{*} \\
(79.2)\end{array}$ & $\begin{array}{c}0.738^{*} \\
(16.57)\end{array}$ & $\begin{array}{c}0.284^{*} \\
(8.35)\end{array}$ & $\begin{array}{c}-0.092^{*} \\
(-3.4)\end{array}$ & $\begin{array}{c}0.291^{*} \\
(31.29)\end{array}$ & 0.76 \\
\hline \multirow{2}{*}{ Pre-crisis period } & $\begin{array}{c}0.76^{*} \\
(49.7)\end{array}$ & $\begin{array}{c}0.8^{*} \\
(12.46)\end{array}$ & $\begin{array}{c}0.44^{*} \\
(8.89)\end{array}$ & $\begin{array}{c}-0.10^{* *} \\
(-2.48)\end{array}$ & $\begin{array}{c}0.28^{*} \\
(22.68)\end{array}$ & 0.85 \\
\hline Crisis-period & $\begin{array}{c}0.75^{*} \\
(69.6)\end{array}$ & $\begin{array}{c}0.9^{*} \\
(17.73)\end{array}$ & $\begin{array}{c}0.76^{*} \\
(17.39)\end{array}$ & $\begin{array}{c}-0.166^{*} \\
(-5.98)\end{array}$ & $\begin{array}{c}-0.126^{*} \\
(-6.42)\end{array}$ & 0.41 \\
\hline
\end{tabular}

The numbers between parentheses are $p$-value. Adj. $R^{2}$ is the adjusted R-squared. *, ${ }^{*}$ represent statistical significance at the $1 \%$ and $5 \%$ levels respectively. 


\subsection{Tests of herding models including volume variable.}

Model III introduces the average volume of transaction as an explanatory variable of the evolution of the CSAD. The empirical results of the model presented in table 5, show that the coefficients of absolute average return, $\eta_{1}$, and squared market return, $\eta_{2}$, in CSAD relationship are significant for all studied periods, so relationship between the CSAD and the average return is non linear. Furthermore, the coefficient $\eta_{2}$ is positive for the whole period and for the pre-crisis period but negative for the crisis period. These findings are consistent with those given by empirical tests of the model II. Based on $\eta_{3}$ and $\eta_{4}$ coefficients in the relationship between CSAD and market volume and the squared market volume respectively, the empirical results show that these coefficients are non significant for the pre-crisis period but significant for the crisis period. For the crisis period the coefficient $\eta_{3}$ is negative and the coefficient $\eta_{+}$is positive confirming herding absence during this period. It appears from the estimations of the CSAD model, where transaction volume was used as explanatory variable, the absence of herd behavior during the pre-crisis period as well as during the crisis period.

Table 5 : Empirical estimation of the model III.

\begin{tabular}{|c|c|c|c|c|c|c|}
\hline \multicolumn{2}{|c|}{ Model III : $C S A D,=\eta_{0}+\eta_{1}\left|R_{m, t}\right|+\eta_{2} R_{m, t}^{2}+\eta_{3}\left|V_{m, t}\right|+\eta_{4} V_{m, t}^{2}+\varepsilon}$, \\
\hline Period & $\hat{\eta}_{0}$ & $\eta_{1}$ & $\hat{\eta}_{2}$ & $\hat{\eta}_{3}$ & $\hat{\eta}_{4}$ & Adj. R2 \\
\hline Whole period & $\begin{array}{c}0.85^{*} \\
(57.32)\end{array}$ & $\begin{array}{c}0.29^{*} \\
(9.61)\end{array}$ & $\begin{array}{c}0.28^{*} \\
(31.68)\end{array}$ & $\begin{array}{c}-0.005 \\
(-0.09)\end{array}$ & $\begin{array}{c}-0.07 \\
(-1.37)\end{array}$ & 0.74 \\
\hline Pre-crisis period & $\begin{array}{c}0.81^{*} \\
(34.65)\end{array}$ & $\begin{array}{c}0.38^{*} \\
(8.99)\end{array}$ & $\begin{array}{c}0.28^{*} \\
(26.13)\end{array}$ & $\begin{array}{c}0.04 \\
(0.37)\end{array}$ & $\begin{array}{c}-0.013 \\
(-1.03)\end{array}$ & 0.84 \\
\hline Crisis-period & $\begin{array}{c}0.78^{*} \\
(51.37)\end{array}$ & $\begin{array}{c}0.82^{*} \\
(20.8)\end{array}$ & $\begin{array}{c}-0.145^{*} \\
(-8.34)\end{array}$ & $\begin{array}{c}-0.125^{* *} \\
(-2.31)\end{array}$ & $\begin{array}{c}0.095^{* *} \\
(2.24)\end{array}$ & 0.41 \\
\hline
\end{tabular}

The numbers between parentheses are $\mathrm{p}$-value. Adj. $\mathrm{R}^{2}$ is the adjusted R-squared. *, ** represent statistical significance at the $1 \%, 5 \%$ levels respectively.

Results of herding behavior on the days when average volume is increasing (decreasing) detailed on table 6 show that during the whole period and the pre-crisis period, $\hat{\theta}_{3}$ and $\hat{\theta}_{4}$ coefficients are positive and statistically significant. This refutes the hypothesis of herding behaviour during the days when the average volume is increasing as well as during the days when the average volume is decreasing. However, during the crisis period, these coefficients are negative and statistically significant ( $\hat{\theta}_{3}=-0.152$ and $=\hat{\theta}_{4}-0.135$ ) showing that the relationship between CSAD and return, described by model IV, is nonlinear (i.e. CSAD decreases as the square return $R_{m, t}^{2}$ increases when average volume is decreasing or increasing). This result confirms that herd behavior is present during the crisis period and that it is associated to both volume movements. We can also conclude that during the crisis period herding behavior is higher when trading volume is increasing $\left(\hat{\theta}_{3}|>| \hat{\theta}_{4} \mid\right)$.

Table 6: Empirical estimation of the model IV.

\begin{tabular}{|c|c|c|c|c|c|c|}
\hline \multicolumn{7}{|c|}{ 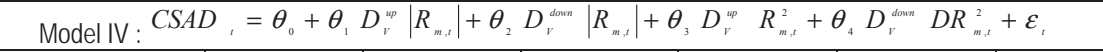 } \\
\hline period & $\hat{\theta}_{0}$ & $\hat{\theta}_{1}$ & $\hat{\theta}_{2}$ & $\hat{\theta}_{3}$ & $\hat{\theta}_{4}$ & Adj. $R^{2}$ \\
\hline Whole period & $\begin{array}{c}0.82^{\star} \\
(83.43) \\
\end{array}$ & $\begin{array}{l}0.32^{*} \\
(9.23) \\
\end{array}$ & $\begin{array}{c}0.38^{*} \\
(10.64)\end{array}$ & $\begin{array}{c}0.2^{*} \\
(15.88)\end{array}$ & $\begin{array}{c}0.28^{*} \\
(28.18)\end{array}$ & 0.75 \\
\hline Pre-crisis period & $\begin{array}{c}0.80^{\star} \\
(54.6)\end{array}$ & $\begin{array}{c}0.32^{\star} \\
(6.79)\end{array}$ & $\begin{array}{c}0.54^{*} \\
(11.03)\end{array}$ & $\begin{array}{c}0.24^{*} \\
(15.86)\end{array}$ & $\begin{array}{c}0.27^{*} \\
(21.5)\end{array}$ & 0.85 \\
\hline Crisis period & $\begin{array}{c}0.756^{*} \\
(69.61)\end{array}$ & $\begin{array}{c}0.835^{\star} \\
(18.39)\end{array}$ & $\begin{array}{c}0.802^{\star} \\
(16.52)\end{array}$ & $\begin{array}{c}-0.152^{*} \\
(-6.97)\end{array}$ & $\begin{array}{l}-0.135^{\star} \\
(-5.85)\end{array}$ & 0.41 \\
\hline
\end{tabular}

The numbers between parentheses are $\mathrm{p}$-value. Adj. $\mathrm{R}^{2}$ is the adjusted R-squared. * represent statistical significance at the $1 \%$ level. 


\subsection{Asymmetry tests of herding behavior to market conditions.}

Since it has been shown that during the political and social crisis in Tunisia, herding behavior appeared regardless of market conditions and trading volume variations, we have to investigate the asymmetry of herd behavior to up and down market and to trading volume movements.

Herding behavior asymmetry to market conditions, is based on the test of the equality of regression coefficients in the relationship between CSAD and squared average return $R_{m, s}^{2}, \varphi_{3}$ when market is up and $\varphi_{4}$ when the market is down. Whereas the asymmetry test of herd behavior to volume variations, consists to test the equality of regression coefficient between CSAD and squared return on days of increasing volume $\theta_{3}$ and decreasing volume, ${ }^{\theta_{4}}$. This implies to test the following null hypothesis $H_{0}: \varphi_{3}=\varphi_{4}$ and $H_{0}: \theta_{3}=\theta_{4}$

The empirical results of herd behavior asymmetry to market movement (up/down market) show (table 7) that the $\mathrm{H}_{0}$ hypothesis is accepted for the period of the crisis, meaning that the herd behavior is similar when market is up or down. The same result was observed from the herd behavior asymmetry tests to volume variations, during the crisis period. Herd behavior is similar for days where volume is increasing and for those where it is decreasing. We can conclude that herd behavior is symmetrical to market conditions, as well as to volume movements.

Table 7: Tests of asymmetry of herd behavior

\begin{tabular}{|c|c|c|c|c|c|c|}
\hline \multirow{2}{*}{} & \multicolumn{2}{|c|}{$\begin{array}{c}\text { Test of asymmetry of herding behavior } \\
\text { to up/down return }\end{array}$} & \multicolumn{2}{c|}{$\begin{array}{c}\text { Test of asymmetry of herd to } \\
\text { increasing/decreasing trading volume }\end{array}$} \\
\cline { 2 - 7 } & \multicolumn{3}{|c|}{ Model II. $H_{0}: \varphi_{3}=\varphi_{4}$} & \multicolumn{3}{c|}{ Model IV. $H_{0}: \theta_{3}=\theta_{4}$} \\
\cline { 2 - 7 } & $\varphi_{3}-\varphi_{4}$ & $\begin{array}{c}\text { Wald test } \\
\text { Chi-square }\end{array}$ & p-value & $\theta_{3}-\theta_{4}$ & $\begin{array}{c}\text { Wald test } \\
\text { Chi-square }\end{array}$ & $p$-value \\
\hline Whole period & -0.3831 & $208.8^{*}$ & 0.000 & -0.086 & $36.43^{*}$ & 0.000 \\
Pre-crisis period & -0.3835 & $87.93^{*}$ & 0.000 & -0.03 & $3.023^{\star * *}$ & 0.082 \\
Crisis period & -0.0408 & 1.768 & $\mathbf{0 . 1 8}$ & -0.016 & 0.334 & $\mathbf{0 . 5 6 3}$ \\
\hline
\end{tabular}

${ }^{*}$, *** represent statistical significance at the $1 \%$ and $10 \%$ levels respectively.

\section{Conclusion}

This paper examines the presence of herding on Tunisian financial market. Some empirical studies have focused on financial crises effect on herding, but the study of the impact of political uncertainty on herding is a subject that lacks analysis. This paper tries to contribute to shed light on this issue by using the return dispersion approach developed by Chang et al (2000) and Chiang and Zheng (2010) to detect herd behavior on the Tunisian stock market globally, during the whole period, then separately on periods before and during the 2011 political and social crisis.

The paper shows that during the crisis period, herd behavior is present regardless to market movements, while during the pre-crisis period herd behavior is associated to up market. By considering the relationship between price and volume, it has been shown that herding is present on the Tunisian financial market only during the crisis period. This behavior is found to be present not only on increasing volume days but also on the decreasing ones. The study of the herding behavior symmetry to market conditions shows that during the political crisis period, herding is similar when market is up and down and volume is increasing and decreasing.

Our study tries to contribute to the empirical literature on the topic of herd behavior and could be extended to other financial markets of countries that experienced political and social crises.

\section{References}

Bhaduri, S., \& Mahapatra, S. (2013). Applying an alternative test of herding behavior: A case study of the Indian stock market. Journal of Asian Economics, 25, 43-52.

Bikhchandani, S., \& Sharma, S. (2001). Herd Behavior in Financial Markets. International Monetary Fund Staff Papers, 47, $279-310$.

Bilson, C.M., Brailsford, J., T.J., \& Vincent C.H. (2002). Hooper The explanatory power of political risk in emerging markets. International Review of Financial Analysis 11, 1-27.

Chang, C. H., \& Lin, S.J. (2015). The effects of national culture and behavioral pitfalls on investors' decision-making: Herding behaviour in international stock markets. International Review of Economics and Finance, 37, 380-392.

Chang, E. C., Cheng, J. W., \& Khorana, A. (2000). An examination of herd behavior in equity markets: An international perspective. 
Journal of Banking and Finance, 24, 1651-1679.

Chau, F., Deesomsak, R., \& Wang, J. (2014). Political uncertainty and stock market volatility in the Middle East and North African (MENA) countries. International Financial Markets, Inst. and Money, 28, 1-19.

Chiang, T. C., \& Zheng, D. (2010). An Empirical Analysis of Herd Behavior in Global Stock Markets. Journal of Banking and Finance, 34, 1911-1921.

Christie, W.G., \& Huang, R.D. (1995). Following the pied piper: Do individual returns herd around the market? Financial Analysts Journal, 51, 31-37.

Crouch, R.L. (1970). The volume of transactions and prices changes on the New York stock exchange. Financial Analysis Journal, 26, 104-109.

Demirer, R., Kutan, A. M., \& Chen, C. (2010). Do investors herd in emerging stock markets? Evidence from the Taiwanese market. Journal of Economic Behavior \& Organization, 76, 283-295.

Dimic, N., Orlov, V., \& Piljak, V. (2015). The political risk factor in emerging, frontier, and developed stock markets. Finance Research Letters, 15, 239-245

Kremer, S,. \& Nautz, D. (2013). Causes and Consequences of Short-Term Institutional Herding. Journal of Banking and Finance, 37, 1676-1686.

Lam., K., \& Qiao S, Z. (2015). Herding and fundamental factors: The Hong Kong experience Pacific-Basin. Finance Journal, 32, 160-188

Le, U. M., \& Truong ., H. N. (2014). An Exploratory Study of Herd Behaviour in Vietnamese Stock Market: A New Method. Asian Journal of Finance \& Accounting, 6, 463-475.

Lee, B.S., \& Rui, O.M. (2002). The dynamic relationship between stock returns and trading volume: domestic and cross-country evidence. Journal of Banking and Finance, 26, 51-73.

Mensah, Y.M., \& Yang, R. (2008). An empirical evaluation of analysts herding behavior following Regulation Fair Disclosur. Journal of Accounting and Public Policy, 27, 317-338.

Nofsinger, R., \& Sias,W. (1999). Herding and Feedback Trading by Institutional and Individual Investors. The Journal of Finance, 54, 2263-2295.

Orlean, A. (1995). Bayesian Interactions and Collective Dynamics of Opinion: Herd Behavior and Mimetic Contagion. Journal of Economic Behavior and Organization, 28, 257-274.

Orlean, A. (1989). Mimetic contagion and speculative bubbles. Theory and Decision, 27, 63-92

Shih, T. L. Hsu, A.C,. Yang, S.J,. \& Lee, C. (2015). Empirical investigation of herding behavior in the East Asian stock markets towards the U.S. market. International Journal of Business and Finance Research, 9, $19-32$.

Venezia, I., Nashikkar, A., \& Shapira, Z. (2011). Firm specific and macro herding by professional and amateur investors and their effects on market volatility. Journal of Banking \& Finance, 35, 1599-1609. 